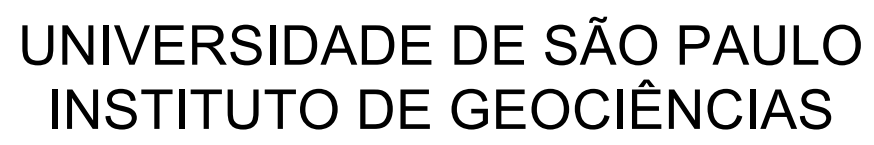

\title{
VARIAÇÕES DA ZONA DE CONVERGÊNCIA INTERTROPICAL E DO NÍVEL RELATIVO DO MAR DURANTE O QUATERNÁRIO TARDIO REGISTRADAS EM DEPÓSITOS EÓLICOS DO NORDESTE E NORTE DO BRASIL
}

André Zular

Orientador: André Oliveira Sawakuchi

Co-orientador: Francisco William da Cruz

\section{TESE DE DOUTORADO}

Programa de Pós-Graduação em Geoquímica e Geotectônica

\author{
Versão corrigida \\ São Paulo \\ 2016
}


ANDRÉ ZULAR

\section{VARIAÇÕES DA ZONA DE CONVERGÊNCIA INTERTROPICAL E DO NÍVEL RELATIVO DO MAR DURANTE O QUATERNÁRIO TARDIO REGISTRADAS EM DEPÓSITOS EÓLICOS DO NORDESTE E NORTE DO BRASIL}

Tese apresentada ao Instituto de Geociências da Universidade de São Paulo como parte dos requisitos para obtenção do título de Doutor em Ciências

Área de concentração: Geoquímica e Geotectônica

Orientador: André Oliveira Sawakuchi Co-orientador: Francisco William da Cruz

Versão corrigida

São Paulo

2016 
Autorizo a reprodução e divulgação total ou parcial deste trabalho, por qualquer meio convencional ou eletrônico, para fins de estudo e pesquisa, desde que citada a fonte.

Ficha catalográfica preparada pelo Serviço de Biblioteca e Documentação do Instituto de Geociências da Universidade de São Paulo

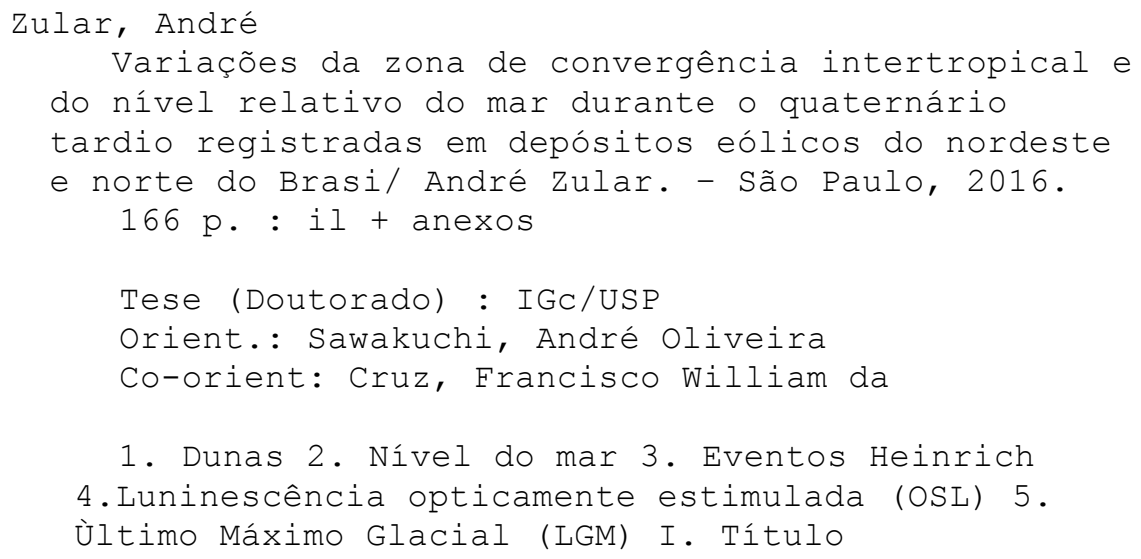




\section{Agradecimentos}

O projeto inicial dessa pesquisa envolvia apenas o estudo da evolução quaternária do campo de dunas costeiras localizado na costa oriental do Rio Grande do Norte. Entretanto, logo no início do primeiro ano de doutorado foi sugerido pelo orientador André Oliveira Sawakuchi acrescentar ao estudo um afloramento nos Lençóis Maranhenses e no ano seguinte mais um em Roraima. 0 primeiro agradecimento então, vai para ele, pelo incentivo de incrementar a pesquisa, pelas frutíferas discussões e por todas as oportunidades oferecidas durante esses quatro anos de projeto, como a ida a vários congressos internacionais e ao estágio no Illinois State Geological Survey, entre outras. 0 segundo agradecimento vai para o co-orientador, Francisco W. Cruz, que será sempre lembrado, além das discussões paleoclimáticas, por me colocar em contato com a colega Giselle Utida para juntarmos nossos esforços no estudo da evolução da costa oriental do Rio Grande do Norte. 0 terceiro agradecimento vai para o Giannini, pelas discussões, bom humor, pelo acompanhamento na viagem de campo ao norte do estado do Rio Grande do Norte e por me aceitar como intruso na viagem de campo para Pinheira. Aproveitando a deixa sobre viagens, agradeço a Lígia Ribeiro e a Milene Fornari, por me convidarem a participar de seus trabalhos de campo nas regiões de Bonito e Laguna. Aprendi muito, obrigado, e espero que tenha ajudado em alguma coisa!

Foram quatro anos de pesquisa e um contato intenso com colegas pósgraduandos e graduandos, professores e funcionários, tanto da IGc como do IAG. Esse espaço é insuficiente para agradecer a todos e tenho receio de esquecer alguém. Para tentar minimizar a falta de memória, vou setorizar as pessoas. A largada será pelo corredor G - superior: Elaine e Jordana, pela ajuda no Malvern, microscópios, lupas e pelas conversas alto-astral. Thays e Luciana, pela ajuda no laboratório e pelos bolos excelentes; Isaac, pela troca de idéias sobre tudo, ajuda no MEV, e pela disposição de seguir com um projeto de catodoluminescência, que acabou não acontecendo. Ainda no piso superior: Sidney Goveia, por me ensinar ArcGis; Antonio da informática por facilitar o acesso aos computadores; Wagner, Zé e Paulo, pela ajuda na infraestrutura do Café Geológico; Boggiani, pelas aulas 
de petrografia. Agora um andar para cima: Solange, pelas boas conversas e ajuda na prestação de contas; Erickson, Airton e Bruno, pela rede e auxílios informáticos; Thelma Samara e Marco Antonio, pela ajuda nos desenhos; Claudio, pela divulgação do Café Geológico; Katherine, Leonardo e Tadeu, pelo apoio acadêmico. Descendo para o térreo: Vasco, pelo auxílio no Franz; Henrique e Claudionor, sempre dispostos a ajudar; Estela, por estar na Geo por tanto tempo; Vinícius, por me explicar muita coisa; Helena, por momentos hilários na companhia de Mr. Biggs; Dorília, por estar sempre sorrindo; Paulo Fiorini, pelas conversas interessantes; Marcelo, Akira e Denílson, por assumirem a organização do Café Geológico; Giselle Utida, Ana Góes, Cristiano Chiessi, Ricardo Trindade, Gelvam e Plínio, pelas discussões científicas interessantes e estímulo; Diego, pelo auxílio no campo em Roraima, infelizmente sem onça por perto; Carlos Guedes pela introdução ao Maranhão; Carlos Mazoca, pela ajuda com imagens de sensoriamento; e finalmente ao André e Adão da portaria por me liberar a catraca quando eu esquecia a carteirinha da USP, dando acesso a esse mundo incrível! 


\section{Resumo}

Os sistemas eólicos na região dos Lençóis Maranhenses no Maranhão, da costa oriental do Rio Grande do Norte e do médio Rio Branco, norte da Amazônia em Roraima, estão sob ação direta da zona de convergência intertropical (ZCIT). As variações da ZCIT controlam a intensidade dos ventos e chuvas nessas regiões, importantes forçantes na dinâmica desses sistemas eólicos, os quais são representados principalmente por campos de dunas. Nos campos de dunas do Maranhão e Rio Grande do Norte, adiciona-se a ação das variações do nível relativo do mar (NRM), que afetam a disponibilidade de sedimentos e o nível freático da planície costeira, que por sua vez influenciam a construção e estabilização dunar. Depósitos eólicos dunares dessas três áreas foram selecionados para investigar a ação de forçantes climáticas e do NRM na sedimentação eólica durante o Pleistoceno tardio e Holoceno. Para tanto, foi utilizada datação por luminescência oticamente estimulada (optically stimulated luminescence, OSL) associada a análises sedimentológicas e geoquímicas de alta resolução em perfis de sucessão de paleodunas. Isto permitiu a identificação de períodos de atividade e estabilização do sistema eólico. 0 registro dos Lençóis Maranhenses abrange o último ciclo glacial, com sedimentos eólicos depositados de 132,20 \pm 7,00 ka (mil anos atrás) até 12,90 \pm 0,60 ka. Nele, se detecta períodos de formação de dunas durante NRM decrescente e baixo. A preservação desses registros entre aproximadamente 71 a 13 ka está relacionada a períodos de maior precipitação durante os eventos Heinrich, quando houve migração persistente da ZCIT para o sul. Já o registro do Rio Grande do Norte abrange o período de 78,98 \pm 8,30 ka até $0,06 \pm 0,01$ ka e indica a formação de campos de dunas também em condições de NRM decrescente e baixo, além de campo de dunas formado sob linha de costa transgressiva e clima predominantemente úmido favorecido pela última fase de subida do NRM, entre o último máximo glacial e o Holoceno médio. 0 estudo no Rio Grande do Norte destaca também a influência dos campos de dunas na fisiografia costeira, onde a interação fluvioeólica proporcionou a formação de lagoas (Lagoa do Boqueirão) no Holoceno Médio. Por sua vez, os depósitos eólicos de Roraima abrangem o período de 21,9 $\pm 1,00$ ka até $1,10 \pm 0,10$ ka e registram o desenvolvimento de campo de dunas a 
partir de areias do médio Rio Branco, com maior taxa de construção dunar entre o último máximo glacial (23 ka) e o evento climático Heinrich 1 (15 ka), quando a incidência de ventos fortes e pluviosidade reduzida nas baixas latitudes do hemisfério norte estão relacionadas a persistente migração ao sul da ZCIT. Os registros dos campos de dunas do MA e RN e RR produzem assim um notável arquivo do efeito das variações da ZCIT e do NRM nos sistemas eólicos das regiões nordeste e norte do Brasil durante o Pleistoceno tardio e Holoceno.

\begin{abstract}
Eolian sand deposits in the region of the Lençóis Maranhenses in Maranhão, the eastern coast of Rio Grande do Norte, and the Middle Branco River, north of the Amazon in Roraima, are under direct influence of the intertropical convergence zone (ITCZ). ITCZ fluctuations control wind intensity and rains in these regions, important forcings controlling the dynamics of eolian systems, that are mainly represented by dunefields. In the coastal dunefields of Maranhão and Rio Grande do Norte, an additional forcing is the relative sea level (RSL), that affects the availability of sediments and controls the water table level of the coastal plain, that in turn influence the construction and stabilization of dunes. Eolian sand deposits in these three areas were selected to investigate the effects of climate and RSL forcings on construction and stabilization of dunes during the late Pleistocene and Holocene using optically stimulated luminescence dating (OSL) associated with sedimentological and geochemical analysis from high-resolution sampling of paleodune succession profiles. The Lençóis Maranhenses record encompasses the last glacial cycle, with eolian sand accumulation from $132.20 \pm$ $7.00 \mathrm{ka}$ (thousand years ago) to $12.90 \pm 0.60 \mathrm{ka}$. This paleoenvironmental archive shows periods of dune construction during falling and low RSL. The preservation of these records between approximately 71-13 ka is related to periods of greater precipitation during Heinrich events, when there were persistent southbound shifts of the ITCZ. The record of the Rio Grande do Norte dunefield from $78.98 \pm 8.30$ to $0.06 \pm 0.01 \mathrm{ka}$ also indicates the formation of dunefields under falling and low RSL in addition to transgressive dunefields formed under rising RSL and wetter climate during the last phase of the
\end{abstract}


deglaciation in the late Holocene. The study in Rio Grande do Norte also highlights fluvial-eolian interplay that affected coastal physiography and promoted the formation of the Boqueirão Lake in the middle Holocene. In turn, the eolian sand deposits of Roraima record accumulation from $21.9 \pm 1.00$ to $1.10 \pm 0.10 \mathrm{ka}$ from Branco River reworked sands. In Roraima, the highest rate of dune construction was between the last glacial maximum (23 ka) and the Heinrich 1 climate event (15 ka), at times of high winds and low rainfall at low latitudes of the northern hemisphere related to persistent southward migration the ITCZ. The dunefield record from Maranhão, Rio Grande do Norte and Roraima thus provide a remarkable archive of the effects of the variations of the ITCZ and RSL in eolian deposits in the northeast and north regions of Brazil during the late Pleistocene and Holocene. 


\section{Apresentação}

Esta pesquisa abrange o estudo da evolução quaternária dos depósitos eólicos (paleodunas) localizados ao norte da cidade de Natal, na região do Rio do Fogo, Rio Grande do Norte, nas adjacências dos Lençóis Maranhenses, no Maranhão, e no médio Rio Branco, norte da Amazônia, em Roraima. Esse estudo investiga a influência das variações da Zona de Convergência Intratropical (ZCIT) na formação e estabilização de campos de dunas durante o Pleistoceno tardio e Holoceno nas baixas latitudes do Hemisfério Sul (Rio Grande do Norte e Maranhão) e do Hemisfério Norte (Roraima). Além disso, o estudo contempla o efeito das variações do nível relativo do mar (NRM) nos campos de dunas costeiros do Maranhão e Rio Grande do Norte. Os métodos, comuns às três áreas de estudo, envolvem cronologia de deposição de sedimentos determinada por luminescência opticamente estimulada (optically stimulated luminescence, OSL) e obtenção de proxies climáticos a partir de análises sedimentológicas e geoquímicas realizadas em perfis de sucessões de dunas amostrados em altaresolução. Os resultados dessa tese de doutoramento são apresentados na forma de três artigos para publicação em periódicos científicos. Estes artigos são apresentados como anexos desse volume. Os artigos que apresentam os resultados desta tese são:

(1) The response of a 120,000-year Late Quaternary dunefield from Lençóis Maranhenses, NE Brazil to sea level and abrupt climate changes

(2) The effect of Late Quaternary sea level and climate changes on coastal evolution in NE Brazil

(3) Climate and landscape changes in northern Amazon driven by ITCZ shifts since the Last Glacial Maximum

O presente texto visa apresentar a síntese dos métodos utilizados e resultados obtidos, bem como discutir de forma integrada os resultados apresentados nos manuscritos anexos. 


\section{Índice}

1. INTRODUÇÃO 4

2. QUESTÕES E CONCEITOS FUNDAMENTAIS 6

2.1. CRONOLOGIA DE DEPÓSITOS EÓlICOS ARENOSOS 6

2.2. REGISTRO LOCAL DE MUDANÇA REGIONAL?

2.3. ZONA DE CONVERGÊNCIA INTERTROPICAL (ZCIT) 8

2.4. VARIAÇõES DA ZCIT DURANTE O QUATERNÁRIO TARDIO 9

2.5. REGISTROS DE VARIAÇÕES DE NRM NO NE DO BRASIL

3. MÉTODOS 11

3.1. UTILIZAÇ̃̃o DE DEPÓSITOS DUNARES EM RECONSTRUÇõES PALEOCLIMÁTICAS

3.2. CRONOLOGIA

3.3. DISTRIBUIÇÃO GRANULOMÉTRICA

3.4. MINERAIS PESADOS

3.5. PETROGRAFIA DE SEÇõES DELGADAS

3.6. ANÁLISE EM MICROSCÓPIO ELETRÔNICO DE VARREDURA (MEV) 13

3.7. FLUORESCÊNCIA DE RAIOS-X E ESPECTROMETRIA GAMA

3.8. SUSCEPTIBILIDADE MAGNÉTICA (SM)

3.9. REFLECTÂNCIA

3.10. SENSIBILIDADE DE TERMOLUMINESCÊNCIA (TL) DE GRÃOS DE QUARTZO

3.11. RADAR DE PENETRAÇÃO NO SOLO (GPR)

4. RESULTADOS 15

\begin{tabular}{lr} 
5. DISCUSSÃO & 18 \\
\hline
\end{tabular}

5.1. RESOLUÇÃO TEMPORAL DO REGISTRO SEDIMENTAR EÓLICO 19

5.2. CONTROLES SOBRE A PRESERVAÇÃO DOS REGISTROS DUNARES NAS ÁREAS DE ESTUDO 21

5.3. A RESPOSTA DOS SISTEMAS EÓLICOS ÀS VARIAÇõES DA ZCIT E NRM 21

REFERÊNCIAS 


\section{Índice de figuras}

FIG. 1 OS DEPÓSITOS EÓLICOS ESTUDADOS NOS ESTADOS DE RORAIMA, MARANHÃO E RIO GRANDE DO NORTE ESTÃO DESTACADOS EM LARANJA. A LOCALIZAÇÃO DOS PONTOS DE AMOSTRAGEM ESTÁ INDICADA EM CADA MANUSCRITO. AS FAIXAS CINZA CLARO (A) E ROSA (B) INDICAM A MÁXIMA EXTENSÃO DA ZCIT NO HEMISFÉRIO NORTE E SUL, RESPECTIVAMENTE.

FIG. 2. AS IDADES OSL OBTIDAS PARA CADA DEPÓSITO EÓLICO ESTUDADO ESTÃO REPRESENTADAS NA BASE DO GRÁFICO. A CURVA DE VARIAÇÃO DO NÍVEL EUSTÁTICO (A) É A SUGERIDA POR THOMPSON E GOLDSTEIN (2006) DE 140 A 7,5 KA. DE 7 KA ATÉ O PRESENTE, É UTILIZADA A CURVA DE NRM HOLOCÊNICA DO RIO GRANDE DO NORTE (CALDAS ET AL., 2006). A VARIAÇÃO NAS CONCENTRAÇÕES DE ZR PARA OS DEPÓSITOS EÓLICOS DO RN, MA E RR ESTÃO INDICADAS EM B, C, E D, RESPECTIVAMENTE. AS BARRAS AMARELAS INDICAM OS PERÍODOS SOBREPOSTOS DE MAIOR TAXA DE ACUMULAÇÃO NOS DEPÓSITOS EÓLICOS DO RN E MA. A BARRA AZUL REPRESENTA O PERÍODO DE MAIOR TAXA DE ACUMULAÇÃO EM RR (FIG. 3). OS LIMITES DOS MIS (MARINE ISOTOPE STAGE), H1, E H6, H3 E H2, SEGUEM AS IDADES PROPOSTAS POR LISIECKI E RAYMO (2005), STRÍKIS ET AL. (2015), E SANCHEZ GOÑI E HARRISON (2010), RESPECTIVAMENTE.

FIG. 3 PERÍODOS DE MAIOR TAXA DE ACUMULAÇÃO NOS DEPÓSITOS EÓLICOS DO MA, RN E RR. AS IDADES COM TAXA DE ACUMULAÇÃO SOBREPOSTAS DOS DEPÓSITOS DO MA E RN SÃO REPRESENTADAS EM BARRAS AMARELAS NA FIG.2.

FIG. 4. OS CAMPOS DE DUNAS ESTUDADOS NOS ESTADOS DO MARANHÃO E NA PORÇÃO ORIENTAL DO RIO GRANDE DO NORTE ESTÃO DESTACADOS EM LARANJA E OS PONTOS DE AMOSTRAGEM ENFATIZADOS EM CÍRCULOS VERDES. A DISTÂNCIA ENTRE ESSES PONTOS E A ISÓBATA DE 25 M FOI MEDIDA DE ACORDO COM A ORIENTAÇÃO DO VENTO. NO MARANHÃO E NO RIO GRANDE DO NORTE, A DISTÂNCIA É DE 47 KM E 32 KM, RESPECTIVAMENTE 
Anexo 1

The response of a 120,000-year Late Quaternary dunefield from Lençóis Maranhenses, NE Brazil to sea level and abrupt climate changes

Anexo 2

The effect of Late Quaternary sea level and climate changes on coastal evolution in NE Brazil

97

Anexo 3

Climate and landscape changes in northern Amazon driven by ITCZ shifts since the Last Glacial Maximum 143 


\section{Introdução}

O último ciclo Glacial foi caracterizado por flutuações globais do nível relativo do mar (NRM) de até $130 \mathrm{~m}$ em amplitude causada por forçantes climáticas em escalas de tempo orbitais (Lambeck e Chappell, 2001). O NRM é considerado um dos principais fatores que afetam a fisiografia e a dinâmica de campos de dunas costeiras (e.g. Warren, 2013). Vários modelos têm sido propostos para explicar a formação de dunas sob condições de elevação ou queda do NRM (Pye e Tsoar, 2009, e referências nele incluídas). Transgressão da linha de costa induzida pela subida do NRM, por exemplo, pode promover a erosão costeira que libera sedimentos para construção de dunas (e..g. Giannini et al., 2007; Lees, 2006; Roy e Thom, 1981). Este modelo tem sido utilizado para explicar a formação de dunas parabólicas ou campos de dunas transgressivos que migram na planície costeira da Austrália (e.g. Thom, 1978; Pye e Bowman, 1984). Por sua vez, regressão da linha costa forçada por queda do NRM pode disponibilizar ao transporte eólico, na ausência de vegetação, grandes quantidades de sedimentos expostos da plataforma continental (e.g. Wood et al., 2012). Além de influir na disponibilidade de sedimentos, o NRM influencia a preservação dos sedimentos eólicos costeiros através do controle do nível de base de erosão (Kocurek e Havholm, 1994). Além dos efeitos do NRM sobre a disponibilidade de sedimentos para transporte eólico, a dinâmica das dunas costeiras é afetada pelo clima que beneficia o transporte de sedimentos para a formação e migração de dunas quando a velocidade do vento é maior que $5 \mathrm{~m} \mathrm{~s}^{-1}$ (e.g. Livingstone et al. 2010). 0 clima também influencia a dinâmica de sistemas eólicos por meio da precipitação que pode favorecer a taxa de crescimento de vegetação e, portanto, influenciar a morfologia dunar, como por exemplo favorecer a formação de dunas vegetadas, e a capacidade de estabilização dos campos de dunas. Embora períodos de estabilização tenham sido frequentemente associados com aumento de vegetação em períodos úmidos (e.g. Fitzsimmons et al., 2009; Kocurek, 1998; Young and Young, 2002), outros trabalhos indicam que há condições em que o vento pode ser o principal fator de controle da estabilização de dunas por vegetação (Ashkenazy et al., 2012; Chase, 2009; Tsoar e Blumberg 2002; Tsoar, 1990, 2005, 2008). A estabilização de dunas através de vegetação pode ocorrer em condições de pluviosidade baixa, de 
menos de $50 \mathrm{~mm}$ ano-1 $^{-1}$ (Ashkenazy et al., 2012; Yizhaq et al., 2009), desde que ventos fracos e/ou baixa disponibilidade de sedimentos produzam condições de baixo aporte eólico $\left(<5 \mathrm{~m} \mathrm{~s}^{-1}\right)$.

Assim, tanto o NRM quanto o clima afetam o desenvolvimento de campos de dunas. Neste contexto, este estudo visa discriminar o efeito do NRM e de forçantes climáticas sobre a dinâmica dunar. Os sistemas eólicos costeiros da região dos Lençóis Maranhenses no Maranhão e da região do Rio do Fogo no Rio Grande do Norte encontram-se sob influência direta do NRM e do clima enquanto que o sistema eólico do médio Rio Branco em Roraima situa-se em área interior sem influência direta do NRM. Esses três depósitos de sedimentos eólicos dunares são produtos da atuação de ventos alísios e precipitação comandados pelas variações hemisféricas da zona de convergência intertropical (ZCIT). Portanto, a ZCIT torna-se peça chave na formação e preservação desses depósitos e objeto importante desse estudo. Para obtenção de indicadores (proxies) climáticos e de NRM, foram efetuadas análises sedimentológicas e geoquímicas a partir de amostragem de alta resolução em perfis de sucessões dunares com cronologia determinada por OSL. No caso dos depósitos eólicos do Rio Grande do Norte, foram adicionados ainda, dados geocronológicos de depósitos eólicos com distribuição regional. Essa tese descreve as condições climáticas e de NRM registradas pela formação e estabilização de campos de dunas nas áreas estudadas. As mudanças climáticas interpretadas a partir dos perfis estudados são comparadas com mudanças regionais e globais interpretadas a partir de proxies climáticos obtidos através da análise de testemunhos de sedimentos marinhos e espeleotemas. 


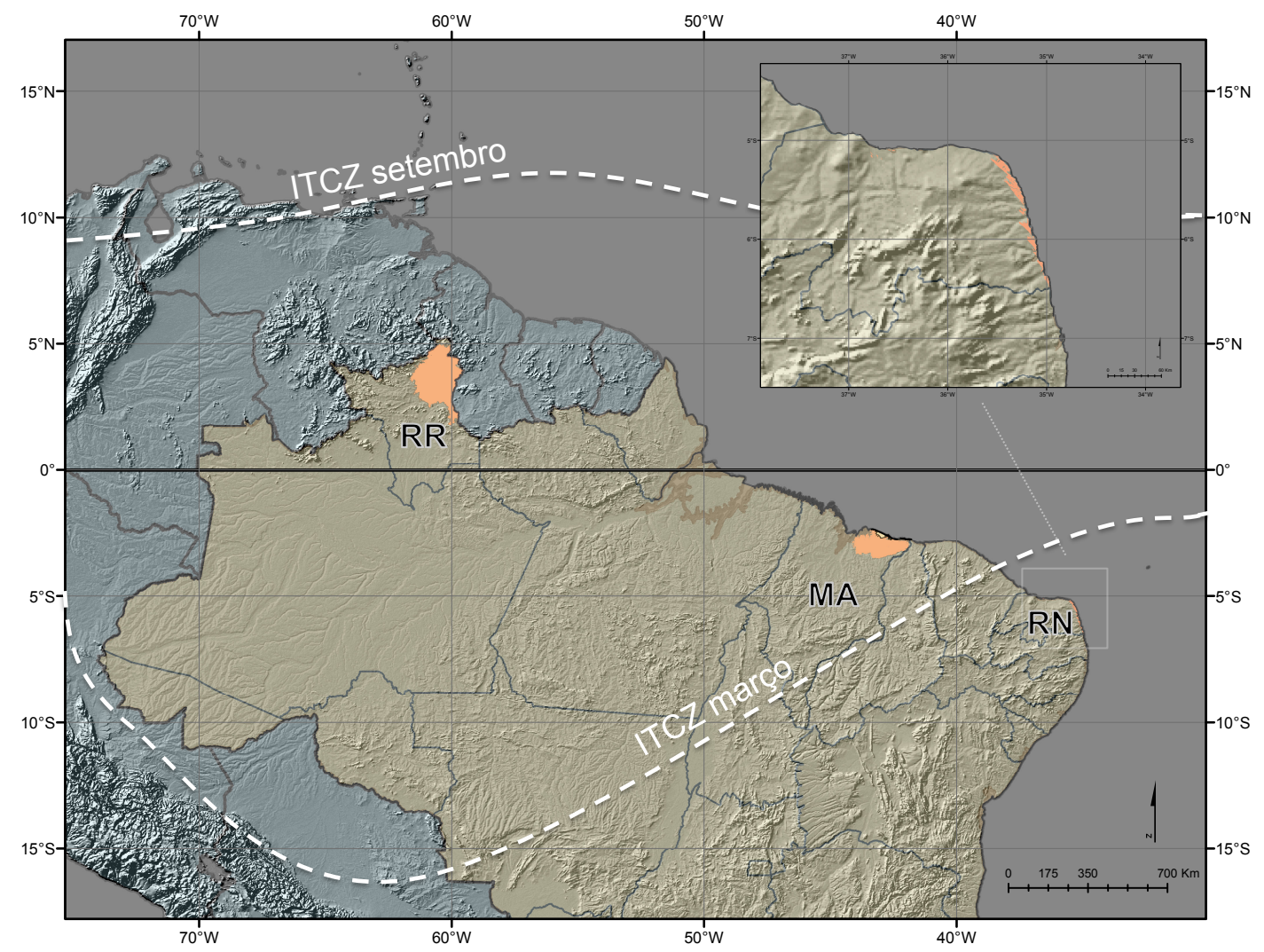

Fig. 1 Os depósitos eólicos estudados nos estados de Roraima, Maranhão e Rio Grande do Norte estão destacados em laranja. A localização dos pontos de amostragem está indicada em cada manuscrito. As posições sazonais da ZCIT foram obtidas em Wang et al., 2004.

\section{Questões e conceitos fundamentais}

\subsection{Cronologia de depósitos eólicos arenosos}

A datação por OSL (Murray e Wintle, 2000; Wintle e Murray, 2006; Rhodes, 2011) tem sido utilizada de modo crescente para determinar cronologias de acumulação de sedimentos eólicos e investigar a resposta dos sistemas eólicos às mudanças climáticas e de NRM (e.g. Tefler e Hesse, 2013; Roskin et al., 2011; Sitzia et al., 2015). No Brasil, onde raramente ocorre a preservação de matéria orgânica em depósitos dunares, o que limita a datação por radiocarbono (e.g. Sawakuchi et al., 2016), a aplicação de OSL em grãos de quartzo para datar fases de agradação e estabilização de dunas eólicas tem crescido rapidamente (e.g. Giannini et al., 2007; Mendes et al., 2015; Sawakuchi et al., 2008; Zular et al., 2012). Estes estudos demonstram que os sedimentos eólicos brasileiros apresentam quartzo de alta sensibilidade de luminescência e 
características adequadas para estimativa de doses de radiação de até 100-150 Gy (Guedes et al., 2013). Estas características associadas a taxas de dose relativamente baixas (0,5-1,0 Gy ka-1) permitem datar sedimentos de dezenas a algumas centenas de milhares de anos (Sawakuchi et al. 2016). Na maioria dos casos, as idades de luminescência apresentam incertezas até 10\%. No caso dos sedimentos eólicos, isto se deve em grande parte à variação das doses equivalentes entre grãos da mesma amostra, devido à heterogeneidades da taxa de dose ou processo de mistura pós-deposicional de grãos de intervalos estratigráficos distintos. Para o intervalo de tempo deste estudo $(<130 \mathrm{ka})$, isto impede o reconhecimento de eventos seculares e limita o estudo à reconstruções de escala milenar. Além de questões inerentes ao método de datação OSL, a resolução temporal dos proxies climáticos também depende das taxas de acumulação e grau de preservação dos depósitos estudados.

\subsection{Registro local de mudança regional?}

Os perfis estudados refletem respostas locais induzidas por variáveis climáticas e de NRM de atuação regional e conectadas ao clima global. Neste caso, torna-se importante discriminar produtos da dinâmica dunar autogênica de efeitos alogênicos associados a elementos de atuação regional ou global, como por exemplo a ZCIT e o nível eustático. Entretanto, a correlação de respostas locais a forçantes regionais não é direta, pois fatores locais são sempre propensos a dominar sobre as tendências regionais (Leighton et al., 2014). Isto é exemplificado pela variação do potencial de preservação de um ponto a outro no mesmo campo de dunas, quando um local pode estar sujeito a maior erosão ou deposição (Kocurek, 1988). A importância do efeito local pode ser minimizada pelo estudo de diversos perfis do mesmo campo de dunas. Alguns autores até sugerem o mínimo de 100 amostras datadas para diferenciar a forçante local da regional (Tefler et al., 2010). Outra opção, comumente utilizada em estudos de reconstrução paleoclimática e adotada nesse estudo, é comparação entre as mudanças reconstruídas a partir de registro local e mudanças baseadas em indicadores independentes associados ao mesmo sistema climático (ex. variações de precipitação ligadas à ZCIT reconstruídas por espeleotemas ou testemunhos de sedimentos marinhos). Nesse sentido, este trabalho foi 
beneficiado pela localização dos campos de dunas estudados. Neles, há ação direta de apenas uma direção de vento responsável pela formação de dunas, os alísios de SE ou NE, controlados pelos deslocamentos da ZCIT. A intensidade desses ventos tem correlação inversa com a precipitação nas áreas de estudo. Nos meses de maior intensidade de ventos, há redução da precipitação e viceversa. Essa correlação, por sua vez, traz a possibilidade de utilizar indicadores de paleoprecipitação da região NE do Brasil medidos em testemunhos de sedimentos marinhos e espeleotemas (e.g. Jaeschke et al., 2007; Cruz et al., 2009, respectivamente) e do norte da América do Sul, na Bacia de Cariaco, Venezuela, estabelecidos a partir de testemunho de sedimentos marinhos (e.g. Haug et al., 2001; Peterson et al., 2000).

\subsection{Zona de convergência intertropical (ZCIT)}

A ZCIT (Fig. 1) é o sistema mais importante para a geração de precipitação sobre as regiões equatoriais oceânicas e continentais adjacentes. Um conjunto de variáveis meteorológicas que atua sobre a faixa equatorial dos oceanos auxilia na sua definição. Estas variáveis incluem a zona de confluência dos ventos alísios, a região do cavado equatorial, as áreas de máxima temperatura da superfície do mar, as áreas de máxima convergência de massas de ar tropical marítimo e a banda de máxima cobertura de nuvens convectivas (e.g. Uvo, 1989). Além do efeito sobre a precipitação, a posição da ZCIT causa o fortalecimento ou enfraquecimento dos ventos alísios de NE e SE, importantes para a formação e estabilização das dunas nas áreas de estudo.

A variação sazonal da ZCIT tem, aproximadamente, o período de um ano, alcançando sua posição mais ao norte durante o verão do hemisfério norte e a sua posição mais ao sul, a cerca de $8^{\circ} \mathrm{S}$, nos anos mais chuvosos de verão no hemisfério sul (e.g. Cavalcanti et al., 2009). A permanência por mais tempo da ZCIT no hemisfério norte ou sul influencia a intensidade das temporadas secas e úmidas nos trópicos, mais do que as estações frias e quentes (e.g. Uvo, 1989). A ocorrência de estações chuvosas extremamente deficientes ou abundantes em precipitação estaria também diretamente relacionada com o deslocamento das Altas Subtropicais do Atlântico Sul (ASAS), responsável pelos ventos alísios de 
SE, e Altas Subtropicais do Atlântico Norte, responsável pelos ventos alísios de NE em direção ao equador, respectivamente (Hastenrath e Heller, 1977). A posição da ZCIT ao norte do equador durante a maior parte do ano está relacionada à existência de águas mais frias na região equatorial leste dos oceanos Pacífico e Atlântico norte (e.g. Geber et al., 2009). Nota-se que a convecção mais forte da ZCIT está mais próxima da costa do Brasil em janeiro e fevereiro e mais próxima à costa da África entre julho e setembro (Cavalcanti et al., 2009).

A região de maior influência da ZCIT nas chuvas do Brasil vai do Amapá/Roraima ao norte do Rio Grande do Norte. Portanto, as áreas de estudo estão situadas em gradiente de longitude dentro na zona de máxima influência da ZCIT. No Maranhão e Rio Grande do Norte, a estação chuvosa vai de janeiro a junho, com máximos de precipitação durante março e abril, meses nos quais a ZCIT atua de forma mais sistemática (Melo, 1997). A partir da costa leste do RN até o sul da Bahia, ocorre a diminuição da zona da influência da ZCIT na precipitação e o aumento da importância das ASAS que avançam no Brasil de leste para oeste, a partir do final do verão e atingem a sua máxima intensidade em julho. No período de maio-julho, durante a máxima convergência dos ventos alísios associados à brisa terrestre e à penetração de sistemas frontais, entre as latitude $5^{\circ} \mathrm{S}$ e $18^{\circ} \mathrm{S}$ (Molion et al., 2000), se observa os ventos de velocidade mais elevada, que atingem até mais de $9 \mathrm{~m} \mathrm{~s}^{-1}$ na área de estudo no RN (DHN, 1974; Fig.2). Já o estado de Roraima, apresenta clima com características antifásicas em relação ao Maranhão e Rio Grande do Norte.

\subsection{Variações da ZCIT durante o Quaternário tardio}

Há evidências de interações intensas entre massas de ar tropical e extratropical na costa brasileira ocorridas durante Pleistoceno tardio e o início do Holoceno (e.g. Cruz et al., 2009; Jaeschke et al., 2007; Ledru e Mourguiart, 2001), o que torna essa região importante para investigar mudanças paleoclimáticas (Cruz et al., 2006). Deslocamentos duradouros para o sul da ZCIT ocorreram frequentemente durante esse período, associados a glaciações do hemisfério norte, ciclos orbitais e eventos abruptos, como por exemplo, os 
eventos Heinrich (H; Heinrich, 1988), e fases de El Niño Southern Oscilation (e.g. Cruz et al., 2007; Jennerjahn et al., 2004). Proxies obtidos a partir de espeleotemas (e.g. Wang et al., 2004), testemunhos de sedimentos lacustres (e.g. Pessenda et al., 2004) e marinhos (e.g. Arz et al., 1998) demonstram variações de precipitação ao longo do Quaternário no Brasil. 0 efeito de eventos $\mathrm{H}$ na sedimentação eólica do NE do Brasil é caracterizado através da análise de vários indicadores descritos nos três manuscritos anexos.

\subsection{Registros de variações de NRM no NE do Brasil}

Estudos sobre mudanças do nível do mar durante o Quaternário tardio e sua influência sobre a geomorfologia costeira do Nordeste do Brasil são limitados por falta de dados de indicadores de NRM regional. Há dados de NRM para períodos específicos, como o do máximo NRM Holocênico no RN, em torno de 6,3 ka (Caldas et al., 2006), ou da taxa de subida do NRM no início do Holoceno, estimada em torno de 6,1 $\mathrm{mm}^{\text {ano-1 }}$ para o RN (Boeski et al., 2015). Assim, utilizou-se registros globais do nível do mar (nível eustático) para poder avaliar o efeito dessa forçante na dinâmica dunar das áreas costeiras estudadas. Dado o caráter relativamente estável da plataforma continental brasileira durante o Quaternário tardio, as variações de NRM são controladas pelas variações eustáticas. 0 registro escolhido foi obtido através da compilação de dados de corais como indicadores de NRM e abrange o período de 148,2 a 7,5 ka (Thompson e Goldstein, 2006; Fig. 2A). Para o período subsequente, de 7 ka até o presente, foi utilizada a curva de NRM holocênica do Rio Grande do Norte baseada em análises de beach rocks e sedimentos lagunares (Caldas et al., 2006). O efeito das variações de NRM na formação e estabilização de campos de dunas no Brasil já foi estudado em condições de NRM relativamente estável a partir do Holoceno médio (e.g. Martinho et al., 2008; Mendes et al., 2015; Zular et al., 2012). Depósitos eólicos pleistocênicos desenvolvidos sob condições de NRM baixo foram estudados sem grande detalhemento cronológico (Barreto et al., 2004; Giannini et al., 2007). 


\section{Métodos}

Os métodos utilizados no presente estudo estão descritos de modo detalhado nos três manuscritos anexos. Esta seção visa abordar de maneira sucinta a utilização de indicadores em estudos paleoambientais de campos de dunas, o motivo de escolha de cada método, bem como os procedimentos e equipamentos adotados nas análises.

\subsection{Utilização de depósitos dunares em reconstruções paleoclimáticas}

Dunas eólicas são frequentemente objetos de pesquisa em estudos paleoambientais do Quaternário devido a sua ampla ocorrência e tendência de preservar vários períodos de acumulação de sedimentos, embora na maioria dos casos de maneira descontínua (e.g. Nanson et al., 1992; Kocurek, 1998; Leighton et al., 2014) e episódica (e.g. Sawakuchi et al., 2008; Roskin et al., 2011). Estudos paleoclimáticos a partir de sedimentos eólicos arenosos estão ligados a determinação de períodos de formação, migração, estabilização e preservação de dunas e relação destas condições com mudanças climáticas. No caso de campos de dunas costeiras, adiciona-se ainda o efeito direto de variações de NRM. Uma vez delimitados esses períodos, pode-se fazer correlação com as condições climáticas e/ou de NRM necessárias para o seu desenvolvimento. Por exemplo, um dos indicadores de estabilização de campos de dunas é a ocorrência de níveis regionais de paleosolos que podem ser preservados em diferentes graus no registro dunar. Quando identificados, os paleosolos definem o limite superior de uma camada que indica fase de atividade eólica (Kocurek, 1998) e são importantes para a reconstrução da história paleoambiental preservada no registro dunar (e.g. Fitzsimmons et al., 2009). Em regiões tropicais, a preservação de paleosolos nem sempre é evidente. Neste contexto, são utilizados indicadores sensíveis a variações na dinâmica de estabilização e ativação de dunas (e.g. Fitzsimmons e Telfer, 2008), como alguns utilizados nesse estudo: medidas granulométricas (diâmetro médio e grau de seleção), geoquímicas (ex. concentração de Zr e razão Zr/Ti) susceptibilidade magnética e reflectância. 


\subsection{Cronologia}

Para obtenção de idades de deposição de sedimentos e definição do modelo de idades para os indicadores sedimentológicos e geoquímicos, amostras selecionadas foram datadas através do método OSL aplicado à alíquotas de quartzo na fração areia. As medidas de luminescência foram realizadas em leitores Risø TL/OSL DA-20. 0 protocolo utilizado para a determinação de dose equivalente de radiação foi o Single-Aliquot Regenerative-Dose (SAR; Murray e Wintle, 2000) aplicado a alíquotas de grãos de quartzo. A taxa de dose foi estimada com auxílio de espectrometria de raios gama de alta resolução por meio de detector de germânio hiperpuro em blindagem ultralow background.

\subsection{Distribuição granulométrica}

Estatísticas de distribuição granulométrica como diâmetro médio e desvio padrão foram usadas para avaliar mudanças texturais em perfis verticais ou comparar unidades eólicas de idades distintas. A análise granulométrica foi efetuada em equipamento Malvern Mastersizer 2000 com acessório Hydro 2000MU. Os resultados foram tabulados de acordo com a classificação granulométrica de Wentworth (1922) e estatísticas granulométricas foram obtidas através do método dos momentos. Os dados granulométricos foram utilizados para interpretar tendências de ativação ou estabilização de dunas. 0 índice Rcs (silte grosso/(silte grosso + areia) foi utilizado para identificar períodos de pedogênese e estabilização dunar.

\subsection{Minerais pesados}

A análise de minerais pesados foi utilizada para investigar a proveniência dos sedimentos. Minerais pesados foram separados na fração areia muito fina (62-125 $\mu \mathrm{m})$ com auxílio de bromofórmio (densidade de 2,83 a 2,89 $\mathrm{g} \mathrm{cm}^{-3}$ ). Foram confeccionadas lâminas com grãos de minerais pesados não-magnéticos, isolados com o separador magnético Franz. Minerais pesados transparentes nãomicáceos foram contados através do método de fita (Galehouse, 1971). 0 índice de proveniência ZRi (proporção de zircão-rutilo; Morton e Hallsworth, 1994) foi obtido através de contagem isolada de 400 grãos de zircão e rutilo. 


\subsection{Petrografia de seções delgadas}

Análises petrográficas de lâminas delgadas foram efetuadas para a identificação de películas (coatings) nos grãos de areia. A partir de blocos intactos de areia previamente secos e impregnados à vácuo com resina epoxy foram confeccionadas lâminas delgadas para análise ao microscópio óptico. A petrografia de lâminas delgadas permitiu caracterizar o tipo e modo de ocorrência de cimentos, cuja composição pode estar relacionada à concentração de elementos químicos específicos (ex. Fe, Ti) e a susceptibilidade magnética.

\subsection{Análise em microscópio eletrônico de varredura (MEV)}

A análise por MEV foi utilizada para avaliar características da textura superficial de grãos relacionadas a fragmentação e dissolução química. Grãos límpidos, sem películas, foram montados em pinos para revestimento superficial com ouro e analisados através do modo de elétrons espalhados e secundários.

\subsection{Fluorescência de raios-X e espectrometria gama}

As análises geoquímicas por fluorescência de raios-X foram efetuadas em equipamentos portáteis onde a medida da intensidade da energia de pico (keV) é proporcional à concentração (ppm) dos elementos nas amostras. A fluorescência de raios-X foi utilizada para medir as concentrações de $\mathrm{Zr}$, Ti e Fe. A concentração de Zr e a razão Zr/Ti foram utilizadas para identificar períodos de pedogênese/deflação e estabilização de dunas. Já a concentração de Fe foi utilizada na análise de sedimentos do Rio Grande do Norte para diferenciar unidades sedimentares, relacionadas a diferentes contribuições de sedimentos das Formações Barreiras e Pós-Barreiras. A espectrometria gama de alta resolução foi utilizada para determinar as atividades e concentrações dos radionuclídeos ${ }^{232} \mathrm{Th}$ e ${ }^{238} \mathrm{U}$. Razões entre estes radionuclídeos permitem discriminar sedimentos de proveniência distinta (e.g. Macdonald et al, 1997; Mohanty et al., 2004).

\subsection{Susceptibilidade magnética (SM)}

A susceptibilidade magnética foi utilizada para identificar intervalos com concentração de minerais portadores de Fe (óxidos e hidróxidos), os quais 
podem indicar períodos de pedogênese mais intensa. A medida de SM de baixa frequência foi efetuada com um sistema Kappabridge MFK1-FA (AGICO Ltd), operado em três frequências de excitação (976, 3904 e 15616 Hz) a um campo de $200 \mathrm{~A} \mathrm{~m}^{-1}$. Os resultados foram normalizados por peso da amostra e expressos em $\mathrm{m}^{3} \mathrm{~kg}^{-1}$.

\subsection{Reflectância}

A análise de reflectância foi utilizada para caracterização indireta da composição dos sedimentos, como por exemplo de películas de cimentos e matéria orgânica. Estes dados também auxiliaram na identificação de horizontes com maior grau de pedogênese, possivelmente associados a umidade superficial. As amostras para medições de reflectância foram misturadas com água destilada e dispostas em lâmina de vidro transparente para secagem por um dia em temperatura ambiente. As lâminas secas foram analisadas com um Espectrofotômetro Minolta CM-700d. Valores de reflectância difusa de cor no espectro visível foram utilizados para se obter o parâmetro de cor a* (CIE, 1978). Esse parâmetro mede a reflectância no espectro do verde ao vermelho e está associado principalmente com o conteúdo de hematita autigênica, que geralmente é formada em períodos mais secos (e.g. Ji et al., 2001).

\subsection{Sensibilidade de termoluminescência (TL) de grãos de quartzo}

Medidas de luminescência foram utilizadas para investigação da proveniência do quartzo, principal componente dos sedimentos estudados. Este método foi aplicado ao estudo dos depósitos do Maranhão. As amostras foram peneiradas para obtenção da fração 150-250 $\mu \mathrm{m}$ e secas em forno por 72 h a 60 ${ }^{\circ} \mathrm{C}$. As frações secas foram subsequentemente montadas em discos de alumínio e submetidas a luz branca por oito horas para esvaziamento de sinais naturais de luminescência. As medidas para o cálculo de sensibilidade TL foram efetuadas em equipamento Risø TL/OSL DA-20 de acordo com sequência descrita em Zular et al. (2015). Os resultados foram normalizados pelo peso de cada alíquota medida. 


\subsection{Radar de penetração no solo (GPR)}

O método de GPR foi utilizado para análise estratigráfia e faciológica em subsuperfície dos depósitos eólicos do Rio Grande do Norte. Os perfis de GPR foram adquiridos com equipamento RIS2 da Ingegneria dei Sistemi com antena de $200 \mathrm{MHz}$ associada a sistema de posicionamento geográfico de GPS (Trimble 5700). Os radargramas foram corrigidos topograficamente.

\section{Resultados}

Os resultados obtidos para cada área de estudo encontram-se descritos e discutidos de modo detalhado nos respectivos manuscritos apresentados nos anexos 1, 2 e 3. As idades OSL dos depósitos eólicos do RN, MA e RR assim como a variação temporal da concentração de $\mathrm{Zr}$ medida em perfis de cada área estudada são apresentadas na Fig. 2. Isto permite a comparação entre os sistemas eólicos das áreas estudadas em termos de fases de estabilização e ativação/agradação de dunas. 0 teor de Zr está associado com a concentração de zircão, a qual indica intensidade de processos pedogênicos e/ou deflacionares e tendência de estabilização dunar. 0 aumento de teor de $\mathrm{Zr}$ pode indicar trapeamento preferencial de grãos de zircão pela vegetação bem como a dissolução de minerais instáveis, sugerindo processos pedogênicos. Os depósitos eólicos do RN e MA apresentam idades entre 132 ka e o presente (dunas ativas). Isto indica a existência de períodos com condições favoráveis ao desenvolvimento de campos de dunas durante todo o Pleistoceno tardio e Holoceno. No entanto, variações do teor de Zr indicam mudanças milenares na atividade do sistema eólico. Taxas mais elevadas de acumulação de sedimentos ocorreram entre 67-58 ka, 43-26 ka e 24-21 ka no depósito eólico do MA, com valores de 0,022 $\mathrm{cm} \mathrm{ano}^{-1}, 0,022 \mathrm{~cm}^{2} \mathrm{ano}^{-1}$, e 0,100 $\mathrm{cm}^{\mathrm{ano}}{ }^{-1}$, respectivamente (Fig. 3). No depósito eólico do RN, as taxas mais elevadas de acumulação foram registradas entre 83-55 ka, 33-22 ka e 11-6 ka, com valores de 0,004 $\mathrm{cm}^{\mathrm{ano}}{ }^{-1}$, $0,011 \mathrm{~cm} \mathrm{ano}^{-1}$, e 0,051 $\mathrm{cm} \mathrm{ano}^{-1}$, respectivamente (Fig. 3). Nota-se que nos depósitos eólicos estudados nestas duas áreas, há formação de dunas durante a fase de queda do NRM do Pleistoceno tardio e, somente no caso de RN, foram 
contempladas dunas formadas durante a fase de NRM alto do Holoceno (Fig. 2A). Já no perfil estudado em RR, a formação de dunas inicia-se no último máximo glacial (LGM, last glacial maximum) há cerca de 23 ka e persiste até cerca de 1 ka, com baixa taxa de acumulação de sedimentos durante o Holoceno. Em Roraima, a maior taxa de acumulação de sedimentos eólicos ocorre entre o LGM e o evento H1 $\left(0,08 \mathrm{~cm}^{a n o^{-1}}\right)$. Os períodos de atividade eólica mais intensa para cada região são apresentados na Fig. 3. As idades mais antigas obtidas nos perfis estudados indicam aproximadamente o início da deposição eólica e as mais novas a estabilização do campo de dunas. Apesar da intensa atividade eólica, os registros estudados demonstram episódios de estabilização de dunas (Fig. 2B, C, D). 0 aumento da concentração de Zr indica atuação de pedogênese interpretada como períodos de ventos mais fracos e de maior pluviosidade. Esses episódios favoreceram a preservação do registro eólico por recobrimento por vegetação. No caso do campo de dunas do médio Rio Branco em Roraima, as variações de estabilização e agradação dunar (taxas de sedimentação e concentração de Zr) são compatíveis com registros regionais que indicam período mais seco pontuado por eventos abruptos de maior precipitação entre o LGM e o início do Holoceno, com destaque para período muito seco durante o H1 (Deplazes et al., 2013; Peterson et al., 2000). A ocorrência de episódios de estabilização como indicado pelo aumento na concentração de $\mathrm{Zr}$ é consistente com modelo de formação do campo de dunas, favorecido pela alternância entre períodos úmidos e secos. Os períodos úmidos são essenciais para suprir sedimentos arenosos ao Rio Branco, os quais estariam disponíveis para transporte eólico na fase seca subsequente de ventos mais fortes.

Observa-se sincronia dos períodos de estabilização e pedogênese dos campos de dunas do RN e MA durante MIS 4 (Marine isotope stage, MIS), MIS 3, MIS 2, LGM e o evento H1 (Fig. 2B, C). Isso sugere que as mudanças climáticas abruptas, em particular durante os eventos H6, H3, H2 e H1 (Fig. 2) tiveram alcance regional, com forte sinal de aumento de precipitação e consequente estabilização de campos de dunas costeiras na costa NE do Brasil. Além disso, a sincronia dos episódios de estabilização sugere que a resposta desses campos de dunas a esses eventos foi relativamente rápida e, dentro das incertezas de idades, sem evidência de atraso em relação às mudanças de precipitação 
registradas em sedimentos marinhos do NE do Brasil (e.g. Arz et al., 1998; Jaeschke et al., 2007; Nace et al., 2014).

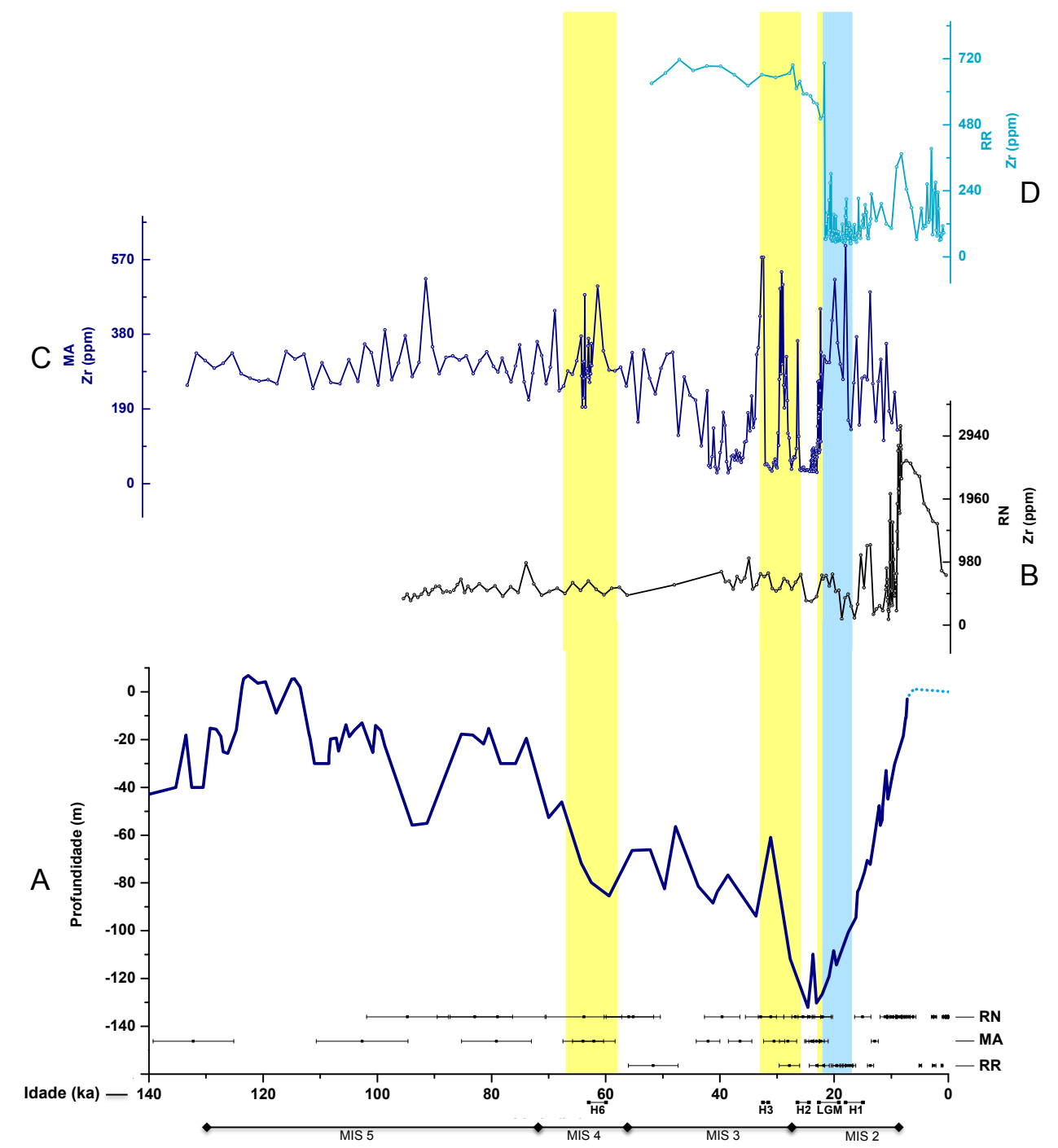

Fig. 2. As idades OSL obtidas para cada depósito eólico estudado estão representadas na base do gráfico. A curva de variação do nível eustático (A) é a sugerida por Thompson e Goldstein (2006) de 140 a 7,5 ka. De 7 ka até o presente, é utilizada a curva de NRM holocênica do Rio Grande do Norte (Caldas et al., 2006). A variação nas concentrações de Zr para os depósitos eólicos do RN, MA e RR estão indicadas em B, C, e D, respectivamente. As barras amarelas e azul indicam os períodos sobrepostos de maior taxa de acumulação nos depósitos eólicos do RN e MA, e RR, respectivamente (Fig. 3). Os limites dos MIS (Marine isotope stage), H1, e H6, H3 e H2, seguem as idades propostas por Lisiecki e Raymo (2005), Stríkis et al. (2015), e Sanchez Goñi e Harrison (2010), respectivamente. 


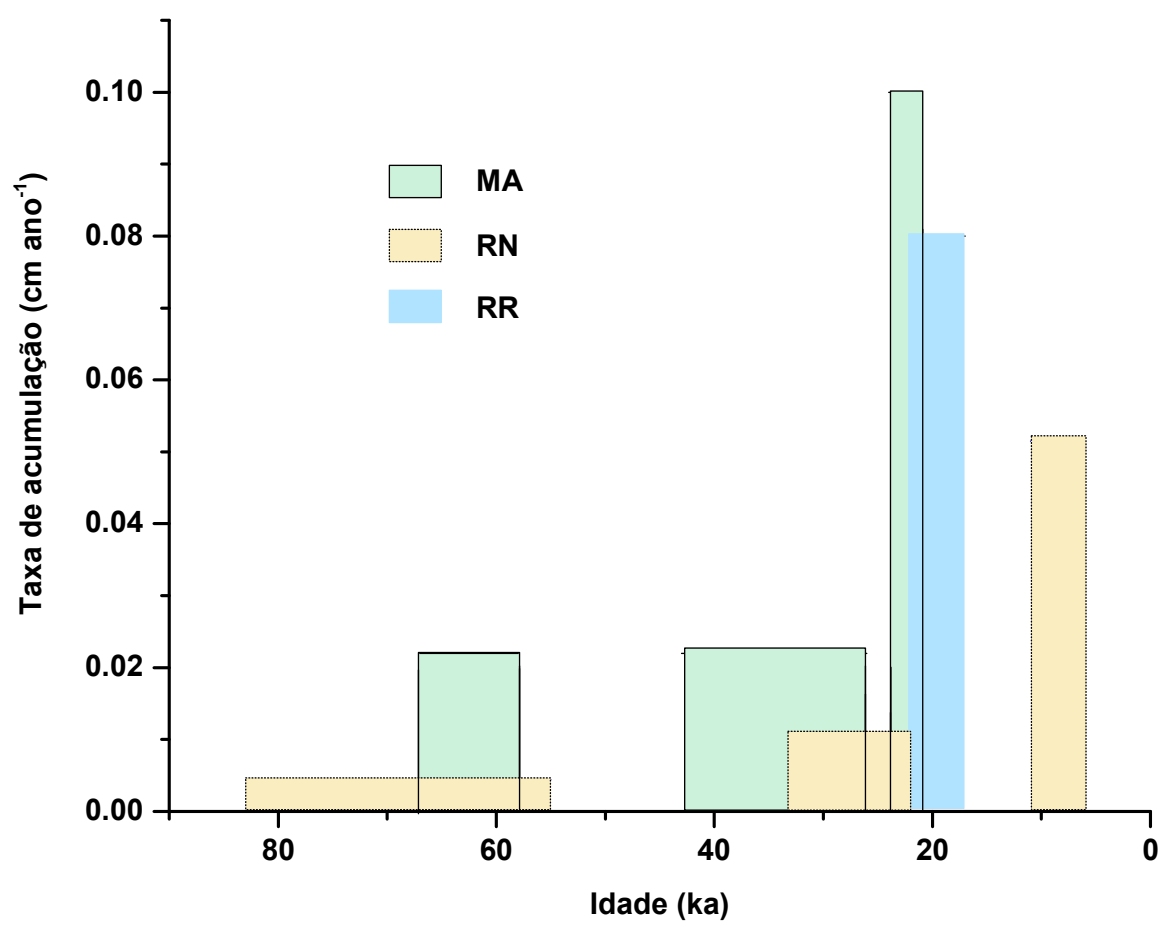

Fig. 3 Períodos de maior taxa de acumulação nos depósitos eólicos do MA, RN e RR. As idades com taxa de acumulação sobrepostas dos depósitos do MA e RN são representadas em barras amarelas na Fig.2.

\section{Discussão}

A discussão detalhada dos resultados obtidos em cada área estudada é apresentada nos seus respectivos manuscritos (anexos 1, 2, e 3). Assim, esta seção discute o significado regional das variações observadas nos sistemas eólicos do RN, MA e RR, principalmente no que diz respeito à influência da ZCIT sobre o clima do nordeste e norte do Brasil. Este tópico é comum às três áreas de estudo.

As sucessões de dunas estudadas registram o efeito da ZCIT na dinâmica eólica, e a do nível relativo do mar, no caso dos campos de dunas do RN e MA. A intensidade de ação dessas forçantes na sedimentação eólica de cada área de estudo foi variável e dependente, por exemplo, da latitude e distância do campo de dunas à linha de costa. Entretanto, o registro dessas forçantes em cada área de estudo foi mais evidente em certos períodos do que em outros. 


\subsection{Resolução temporal do registro sedimentar eólico}

0 erro inerente do método de datação OSL, geralmente de 5 a 10\%, combinado com o potencial de preservação de cada depósito limita o estudo à reconstrução de mudanças de escala milenar. A escolha da densidade de amostras para datação de cada afloramento é feita, idealmente, para que se obtenha representação adequada da dinâmica de construção do depósito e do seu significado paleoambiental (Leighton et al., 2014). Esses autores salientam que o fator mais importante para estimar a quantidade de amostras a serem coletadas é a identificação de estruturas sedimentares macroscópicas. Entre as estruturas mais importantes destacam-se feições como estratificações cruzadas (e.g. Bristow et al., 2007) e paleosolos (e.g. Munyikwa, 2000), as quais permitem individualizar unidades deposicionais separadas por descontinuidades. Entretanto, mesmo adotando estas orientações, a descontinuidade temporal do registros eólicos limitam as reconstruções paleoambientais (e.g. Munyikwa, 2000). As superfícies de separação estratigráfica podem representar hiatos deposicionais significativos, os quais indicam períodos de estabilização, de deposição seguida de erosão ou de by-pass de sedimentos importantes para elucidar a evolução paleoambiental, porém desprovidos de registro sedimentar. No caso dos depósitos estudados, a ausência de superfícies nítidas de separação estratigráfica associada ao caráter maciço das sucessões de paleodunas, impede a definição de arcabouço estratigráfico prévio à coleta de amostras para datação. Assim, houve a necessidade de se optar por um intervalo arbitrário de amostragem para datação OSL das sucessões dunares estudadas. No afloramento dos Lençóis Maranhenses optou-se por utilizar intervalo de amostragem de $1 \mathrm{~m}$. Já no Rio Grande do Norte, foi utilizado intervalo de $0,5 \mathrm{~m}$ ou inferior, nos primeiros 4,8 m de profundidade. Em Roraima, utilizou-se o intervalo de 0,5 m nos primeiros 3,3 $\mathrm{m}$ de profundidade e $1 \mathrm{~m}$ para as amostras do intervalo mais profundo. Esses intervalos de amostragem para análise cronológica de sucessões de dunas são consistentes com o que é apresentado em outros estudos (e.g. Roskin et al., 2011, Stone e Thomas, 2008). Entretanto, grandes intervalos (> 1 m) de amostragem definidos de modo arbitrário podem ser inadequados para registrar a variação de taxas de acumulação de sedimentos. Como exemplo, há o 
estudo efetuado no sudoeste do Kalahari onde houve a necessidade de reduzir de $1 \mathrm{~m}$ para $0,5 \mathrm{~m}$ o intervalo de amostragem de maneira a registrar as variações de taxa de acumulação (Stone e Thomas, 2008). Porém, nova amostragem nem sempre é possível do ponto de vista prático. Nos casos estudados, os intervalos de amostragem apresentaram-se adequados em termos das incertezas das idades OSL e das taxas de acumulação registradas, uma vez que amostras adjacentes apresentaram idades próximas ao limite da sobreposição pelos respectivos erros. A variação da taxa de acumulação dos sedimentos nos depósitos estudados constituiu fator determinante para a resolução temporal das reconstruções paleoclimáticas. Nos depósitos de Roraima, por exemplo, o período entre o LGM e H1 abrange 5,5 m de sedimentos depositados em menos de 8.300 anos. Este é o período de maior resolução temporal para reconstruções paleoclimáticas nesta área de estudo. As elevadas taxas de acumulação registradas na série temporal indicam, portanto, períodos de ventos intensos e alta disponibilidade de sedimentos permitindo assim a identificação de variações paleoambientais de escala submilenar através de nossos proxies. Os períodos subsequentes ao LGM/H1 necessitariam de maior densidade amostral para identificar variações da escala temporal registrada no período correspondente ao LGM/H1, além das incertezas de idade inerentes do método de datação OSL. A baixa resolução temporal é capaz de fornecer apenas informações de tendência geral e reconstruir variações de escala milenar. Da mesma maneira, os períodos de 12,2-6 ka, MIS 3 e MIS 2, no Rio Grande do Norte e nos Lençóis Maranhenses (Fig. 2), respectivamente, representam intervalos de maior resolução temporal. São nesses períodos que as informações trazidas pelos proxies sensíveis a mudanças climáticas e/ou de NRM são mais valiosas. Por exemplo, no caso dos Lençóis Maranhenses, o aumento de valores de Rcs e Zr/Ti durante o MIS 3 e MIS 2 (Anexo 2) sinalizam períodos de estabilização do campo de dunas, correlacionados com eventos climáticos episódicos de aumento de precipitação. Já os períodos correspondentes ao MIS 4 e MIS 5 apresentam baixa resolução temporal, o que impede a identificação de variações abruptas milenares a submilenares nos proxies. Consequentemente, a reconstrução paleoambiental é limitada. 


\subsection{Controles sobre a preservação dos registros dunares nas áreas de estudo}

A preservação dos sedimentos eólicos está relacionada ao nível de base de erosão (Kocurek e Havholm, 1993). Nas áreas de estudo esse nível é controlado por vegetação ou influência da precipitação e nível do mar sobre o nível freático, já que forçantes tectônicas não foram atuantes na escala de tempo analisada. Embora não haja, em nenhum dos três depósitos estudados, feições visíveis que indiquem a presença de níveis restritos de paleosolos, os proxies utilizados apresentam mudanças significativas que indicam a ocorrência de períodos pedogênicos. Esses períodos, intercalados entre episódios de acumulação eólica beneficiaram a preservação dos sedimentos sotopostos. Além disso, os paleosolos indicam também que a retomada da fase de acumulação eólica foi através de ventos com velocidade insuficiente para destruir evidências de pedogênese por meio de erosão/deflação. Nos depósitos dos Lençóis Maranhenses e do Rio Grande do Norte, a preservação dos registros eólicos de MIS 4-2 (Fig. 2) está ligada ao aumento abrupto de precipitação, quando a ZCIT estava deslocada mais ao sul por mais tempo, ou seja, em períodos de ventos mais fracos. Assim, a ocorrência desses períodos aumentou o potencial de preservação, que teria sido baixo durante os períodos de deflação intensa, como durante o LGM. Da mesma maneira, a preservação do registro dunar de Roraima em períodos de deflação, como em períodos posteriores ao $\mathrm{H} 1$, sugere a ocorrência de episódios pedogênicos, associados ao aumento da precipitação que nesse caso é responsável também pelo manutenção da disponibilidade dos sedimentos do Rio Branco por meio da alternância entre episódios de cheia e seca. Nos períodos subsequentes aos eventos de aumento de precipitação, com ventos mais fortes e relativamente mais secos, esses sedimentos contribuiriam para a formação das dunas.

\subsection{A resposta dos sistemas eólicos às variações da ZCIT e NRM}

Há uma sobreposição de períodos de maior atividade eólica nos depósitos do Rio Grande do Norte e Maranhão durante 67-58 ka, 33-26 ka, e 23-22 ka (Fig. 3). A deposição eólica nestas duas localidades ocorreu predominantemente em 
condições de queda de NRM (Fig. 2A), o que sugere que a plataforma continental exposta não foi completamente vegetada nesses períodos, havendo então disponibilidade de sedimentos retrabalhados diretamente da plataforma exposta que acumularam na zona de intermaré para serem levados pelo vento. A atividade eólica registrada nesse dois campos, representada pela taxa de acumulação de sedimentos, é significativamente maior no depósito do Maranhão (Fig. 3). Isso pode estar relacionado com a largura da plataforma (Fig. 4) e a elevada disponibilidade de sedimentos na área fonte (Kowsmann and Costa, 1979; Vital, 2014) devido ao barramento hidráulico da corrente de deriva litorânea situadas a oeste do campo de dunas dos Lençóis Maranhenses (Sawakuchi, 2006) associada a ventos mais fortes. Por sua vez, o depósito eólico do Rio Grande do Norte apresenta largura de plataforma menor e não há ao norte do depósito drenagens que possam barrar a deriva litorânea de direção norte e favorecer um acúmulo maior de sedimentos na zona de intermaré. A estabilização desses depósitos provavelmente teve a contribuição dos eventos H6, H3, H2 e H1 (Fig. 2) que estão associados a ventos mais fracos e maior pluviosidade. Esses períodos são indicados pelo aumento da concentração de $\mathrm{Zr}$ nos sedimentos eólicos (Fig. 2C e D), indicativo de processos pedogênicos. A ocorrência desses eventos de escala milenar em períodos de alta taxa de acumulação promoveu processos pedogênicos de maior intensidade e favoreceu a preservação dos sedimentos eólicos acumulados em períodos anteriores por protegê-los de processos deflacionares.

No caso do depósito eólico de Roraima, a maior taxa de acumulação entre 22-17 ka, abrange o LGM e H1. Embora haja dados de testemunhos marinhos obtidos na Bacia de Cariaco (e.g. Deplazes et al., 2013; Fig. 1) que sugiram persistente migração ao sul da ZCIT durante o H1, indicativa de período mais seco e de ventos fortes, condições climáticas nessa região durante o LGM não estão bem esclarecidas. As divergências ocorrem devido ao efeito do NRM mais baixo durante o LGM que teria isolado a Bacia de Cariaco do mar do Caribe (e.g. Hodell et al., 2008). Entretanto, alguns autores sugerem que a ZCIT permaneceu em média mais ao sul durante esse período (e.g. Koutavas e Lynch-Stieglitz, 2004; Baker et al., 2009). O registro do início de formação do depósito eólico de Roraima durante o LGM com alta taxa de acumulação de sedimentos reforça essa 
última hipótese de clima mais seco e com ventos fortes devido a migração mais persistente ao sul da ZCIT.

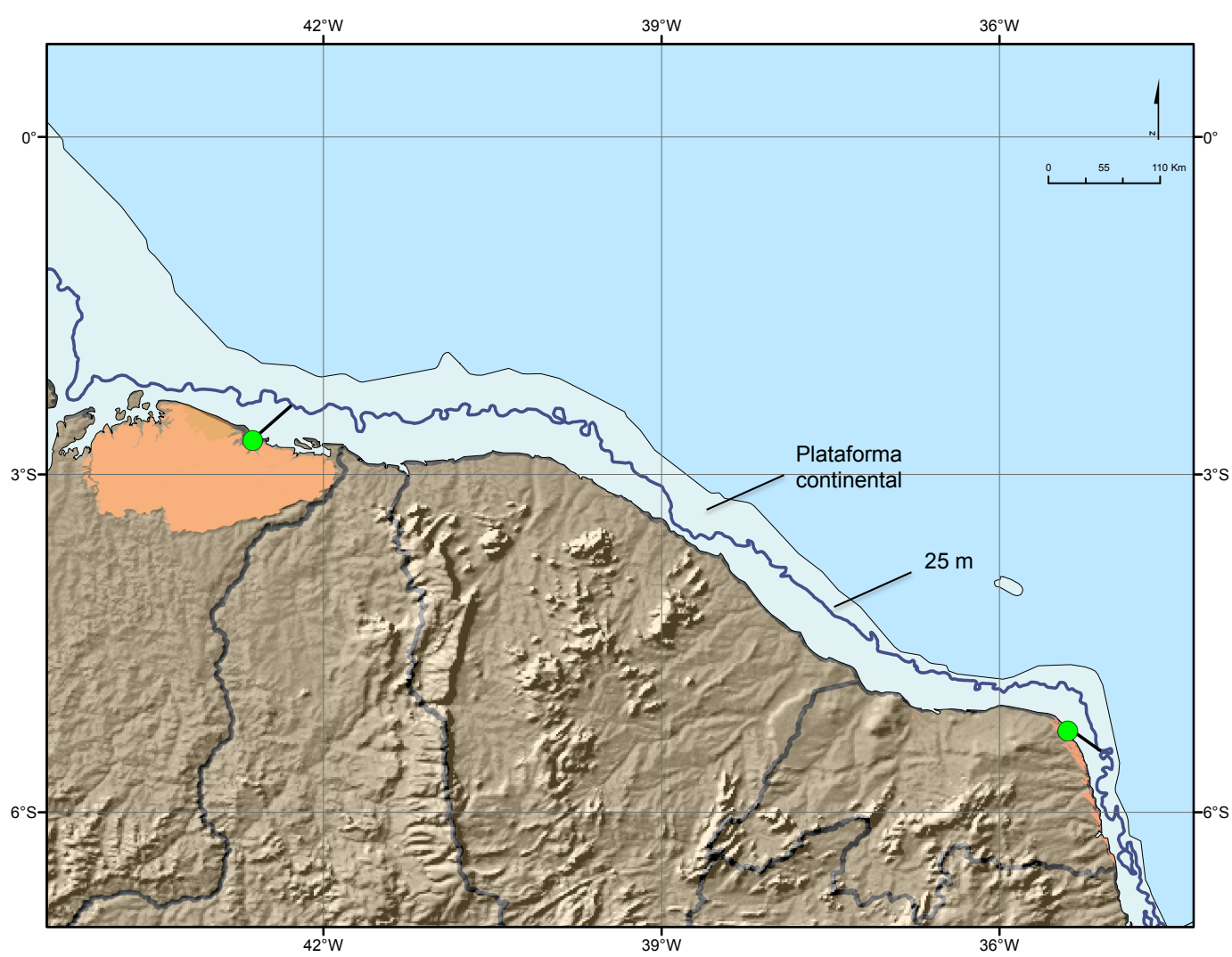

Fig. 4. Os campos de dunas estudados nos estados do Maranhão e na porção oriental do Rio Grande do Norte estão destacados em laranja e os pontos de amostragem enfatizados em círculos verdes. A distância entre esses pontos e a isóbata de $25 \mathrm{~m}$ foi medida de acordo com a orientação do vento. No Maranhão e no Rio Grande do Norte, a distância é de 47 km e 32 km, respectivamente

0 registro eólico estudado no ponto de amostragem do RN inclui tanto dunas formadas em fase de NRM descendente e linha de costa regressiva quanto em fase de NRM ascendente e linha de costa transgressiva. Esse quadro de dinâmica dunar costeira relacionado a diferentes fases do NRM é também descrito em outros locais. Por exemplo, dunas costeiras na península arábica se formaram em condições de nível relativo do mar baixo do LGM. Wood et al. (2012) sugerem que nessa região a plataforma continental exposta estava esparsamente vegetada durante o LGM, havendo então disponibilidade de sedimentos para a formação de depósitos eólicos arenosos. Na mesma região, há formação de campos de dunas durante a transgressão da linha de costa holocênica (Atkinson et al., 2012). 0 importante, nessas duas condições contrastantes de NRM foi a disponibilidade de sedimentos levados para a zona 
de intermaré para subsequente transporte eólico, já que os ventos permaneceram fortes nos dois períodos. É razoável supor que sedimentos foram levados para essa zona de intermaré da costa do MA durante a transgressão da linha de costa holocênica. Por que, então, não está registrada a formação de dunas durante esse período no nosso ponto de amostragem enquanto temos o registro no RN? Hoje, no RN há maior migração das dunas costa adentro, pois estas são vegetadas e deflacionares, sujeitas a ventos fortes mas com suprimento de sedimentos limitado. Ventos de mais de $8 \mathrm{~m} \mathrm{~s}^{-1}$ são registrados além da Lagoa do Boqueirão, a cerca de $25 \mathrm{~km}$ da costa oriental do Rio Grande do Norte. Por isso, estas dunas avançam mais costa adentro. Já no MA as dunas são de maior aporte (dunas livres) e portanto com mais agradação que migração. Nos Pequenos Lençóis Maranhenses, região do nosso ponto de amostragem, ventos de mais de $5 \mathrm{~m} \mathrm{~s}^{-1}$ atingem no máximo $10 \mathrm{~km}$ costa adentro. É razoável supor que essas diferenças de intensidade e alcance dos ventos nessas duas regiões tenham sido semelhantes durante o Quaternário tardio. Num sistema de deposição eólica onde a disponibilidade de sedimentos é grande como nos Lençóis Maranhenses (Sawakuchi, 2006), o fator limitante para a formação de dunas, considerando que há espaço de acomodação, é o vento. Portanto, supõese que os ventos não foram suficientemente fortes na costa maranhense no início do Holoceno para transportar areia até o nosso ponto de amostragem, quando a linha de costa estava pelo menos a $20 \mathrm{~km}$ de distância. Já na costa do Rio Grande do Norte a diminuição da intensidade dos alísios de SE não deve ter afetado tão drasticamente o transporte eólico, como mostra o nosso registro. Outra possibilidade para explicar a ausência de registro de dunas formadas no início do Holoceno no nosso ponto de amostragem no Maranhão, agindo em conjunto com a forçante climática, poderia estar relacionada a largura da plataforma continental (Fig. 4). No MA a largura e a quebra da plataforma são de $75 \mathrm{~km}$ e 70 m, respectivamente (Kowsmann and Costa, 1979), enquanto que no RN esses valores são em média $40 \mathrm{~km}$ e $60 \mathrm{~m}$, respectivamente (Vital et al., 2010). Embora os pontos de coleta de amostras da sucessão de dunas nos dois estados estejam a uma distância aproximadamente igual da presente linha de costa, medida na direção dos ventos preponderantes ( $25 \mathrm{~km})$, essa situação não era a mesma no início do Holoceno. Isso teria afetado a disponibilidade de areia para a formação 
de campo de dunas transgressivos de maneira desigual nos dois depósitos já que a taxa de subida do NRM foi mais alta no RN. Estudos realizados na Austrália mostram que a formação de campos de dunas transgressivas no início do Holoceno deu-se principalmente devido as altas taxas de subida do NRM nesse período (e.g Thom, 1978). Assim, a maior distância da linha de costa ao nosso afloramento, no caso do Maranhão, poderia ter contribuído também para limitar a disponibilidade e o alcance do transporte eólico das areias disponíveis da zona de intramaré até o ponto de amostragem.

Sem dúvida, houve a formação de dunas em períodos de subida do NRM na costa maranhense, mas é provável que essas dunas tenham sido em parte canibalizadas com o avanço da linha de costa ou que seu registro esteja presente em regiões mais próximas da linha de costa atual.

\section{Conclusão}

Os depósitos eólicos costeiros dos Lençóis Maranhenses e Rio Grande do Norte foram iniciados a pelo menos 132,000 e 94,750 anos atrás, respectivamente. Os períodos de maior taxa de acumulação, comuns aos dois depósitos, ocorreram em 67-58 ka, 33-26 ka, e 23-22 ka em condições de queda de nível relativo do mar. Nessa condição, a plataforma exposta pela regressão da linha de costa apresentava-se menos vegetada, de maneira a não impedir o transporte eólico de sedimentos recém disponíveis. A estabilização do registro eólico desses períodos deu-se através de ventos mais fracos e aumento de pluviosidade durante os eventos climáticos Heinrich. Esses períodos estão relacionados com a migração ao sul mais persistente da ZCIT, com potencial de promover a preservação dos registros dunares através de processos pedogênicos mais intensos e desenvolvimento de vegetação. 0 depósito eólico do Rio Grande do Norte apresenta também a formação de dunas transgressivas durante o último episódio de subida do NRM durante o Holoceno. A formação desse campo de dunas foi beneficiada pelo aporte de novos sedimentos associado a ventos fortes A formação do depósito eólico em Roraima deu-se nas condições mais áridas e com ventos mais intensos do último máximo glacial e evento climático $\mathrm{H} 1$ a partir de aporte de sedimentos fluviais. Isto também foi 
proporcionado pela migração da ZCIT para sul e indica condições climáticas antifásicas entre o norte da Amazônia (mais seca) e a costa nordeste (mais úmida) do Brasil durante o LGM e H1. A estabilização do campo de dunas de Roraima foi beneficiada por tendência de ventos reduzidos e pluviosidade mais intensa, iniciada após o evento climático H1 e persistente durante todo o Holoceno.

\section{Referências}

Arz, H. W., Patzold, J., Wefer, G. 1998. Correlated millennial-scale changes in surface hydrography and terrigenous sediment yield inferred from last-glacial marine deposits off northeastern Brazil. Quaternary Research, 50, 157-166.

Ashkenazy, Y., Yizhaq, H., Tsoar, H. 2012. Sand dune mobility under climate change in the Kalahari and Australian deserts. Climatic Change, 112, 901- 923.

Atkinson, O. A. C., Thomas, D. S. G., Goudie, A. S., Parker, A. G. 2012. Holocene development of multiple dune generations in the northeast Rub' al-Khali, United Arab Emirates. Holocene, 22, 179-189.

Baker, P. A., Fritz, S. C., Burns, S. J., Ekdahl, E., Rigsby, C. A. 2009. The nature and origin of decadal to millennial scale climate variability in the southern tropics of South America: the Holocene record of Lago Umayo, Peru. In Past Climate Variability in South America and Surrounding Regions (pp. 301-322). Springer Netherlands.

Barreto, A. M. F., Suguio, K., Bezerra, F. H. R., Tatumi, S. H., Yee, M., Giannini, P. C. F. 2004. Geologia e geomorfologia do Quaternário costeiro do Estado do Rio Grande do Norte. Geologia USP. Série Científica, 4, 1-12.

Boski, T., Bezerra, F. H., de Fátima Pereira, L., Souza, A. M., Maia, R. P., Lima-Filho, F. P. 2015. Sea-level rise since 8.2 ka recorded in the sediments of the PotengiJundiai Estuary, NE Brasil. Marine Geology, 365, 1-13.

Bristow, C. S., Duller, G. A. T., Lancaster, N., 2007. Age and dynamics of linear dunes in the Namib Desert. Geology, 35, 555-558. 
Caldas, L. H. O., Stattegger, K., Vital, H. 2006. Holocene sea-level history: evidence from coastal sediments of the northern Rio Grande do Norte coast, NE Brazil. Marine Geology, 228, 39-53.

Cavalcanti, I. F., Ferreira, N. J., Silva, M. G. A. J., Dias, M. A. F. S. 2009. Tempo e clima no Brasil. Oficina de textos, $463 \mathrm{pp}$.

Chase, B. 2009. Evaluating the use of dune sediments as a proxy for palaeoaridity: A southern African case study. Earth-Science Reviews, 93, 31-45.

CIE. Commission Internationale de l'Eclairage. 1978. Recommendations on Uniform Color Paces, Color Difference and Psychometric Color Terms. CIE, Paris, Colorimetry, Publication 15, Supplement 2, 21 pp.

Cruz Jr., F. W., Burns, S. J., Karmann, I., Sharp, W. D., Vuille, M. 2006. Reconstruction of regional atmospheric circulation features during the late Pleistocene in subtropical Brazil from oxygen isotope composition of speleothems. Earth and Planetary Science Letters, 248, 494-506.

Cruz Jr., F. W., Burns, S. J., Jercinovic, M., Karmann, I., Sharp, W. D., Vuille, M. 2007. Evidence of rainfall variations in Southern Brazil from trace element ratios $(\mathrm{Mg} / \mathrm{Ca}$ and $\mathrm{Sr} / \mathrm{Ca})$ in a Late Pleistocene stalagmite. Geochimica et Cosmochimica Acta 71, 2250-2263.

Cruz Jr., F. W., Vuille, M., Burns, S. J., Wang, X., Cheng, H., Werner, M., Edwards, R. L., Karmann, I., Auler, A. S., Nguyen, H. 2009. Orbitally driven east-west antiphasing of South American precipitation. Nature Geosciences, 2, 210-214.

Deplazes, G., Lückge, A., Peterson, L. C., Timmermann, A., Hamann, Y., Hughen, K. A., Röhl, U., Laj, C., Cane, M. A., Sigman, D. M., Haug, G. H. 2013. Links between tropical rainfall and North Atlantic climate during the last glacial period. Nature Geoscience, 6, 213-217.

DHN. 1974. Ministério da Marinha. Diretoria de Hidrografia e Navegação. XLVI Comissão Oceanográfica: Operação GEOMAR III, Noc. Almirante Saldanha. Rio de Janeiro. 109 p. 
Fitzsimmons, K. E., Telfer, M. W., 2008. Complexities in the preservation and interpreta- tion of Late Quaternary dune records: examples from the Tirari Desert, Australia and the southwestern Kalahari, South Africa. Chungará, 30, 295-308.

Fitzsimmons, K. E., Magee, J. W., Amos, K. J. 2009. Characterisation of aeolian sediments from the Strzelecki and Tirari Deserts, Australia: implications for reconstructing palaeoenvironmental conditions. Sedimentary Geology, 218, 6173.

Galehouse, J.S., 1971. Point Counting. In: Carver, R.E. (ed.), Procedures in Sedimentary Petrology. Wiley, New York, pp. 385-407.

Geber, B. D. A., de Aragão, J. O., de Melo, J. S., da Silva, A. P., Giongo, P. R., Lacerda, F. F. 2009. Relação entre a precipitação do leste do Nordeste do Brasil e a temperatura dos oceanos. Revista Brasileira de Engenharia Agrícola Ambiental, $13,462-469$.

Giannini P. C. F., Sawakuchi A. O., Martinho C. T., Tatumi S. H. 2007. Eolian depositional episodes controlled by Late Quaternary relative sea level changes on the Imbituba-Laguna coast (southern Brazil). Marine Geology, 237,143-168.

Guedes, C. C., Sawakuchi, A. O., Giannini, P. C., Dewitt, R., Aguiar, V. A. 2013. Luminescence characteristics of quartz from Brazilian sediments and constraints for OSL dating. Anais da Academia Brasileira de Ciências, 85, 1303-1316.

Hastenrath, S., L. Heller, 1977: Dynamics of climatic hazards in north-east Brazil. Quarterly Journal of Research Meteorological Society, 110, 411-425.

Haug, G. H., Hughen, K. A., Sigman, D. M., Peterson, L. C., Röhl, U. 2001. Southward migration of the intertropical convergence zone through the Holocene. Science, 293, 1304-1308.

Heinrich, H. 1988. Origin and consequences of cyclic ice rafting in the northeast Atlantic Ocean during the past 130,000 years. Quaternary research, 29, 142-152. 
Hodell, D. A., Anselmetti, F. S., Ariztegui, D., Brenner, M., Curtis, J. H., Gilli, A., Grzesik, D. A., Guilderson, T. J., Mueler, A. D., Bush, M. B., Correa-Metrio, A. , Escobar, J., Kutterolf, S. 2008. An 85-ka record of climate change in lowland Central America. Quaternary Science Reviews, 27, 1152-1165.

Jaeschke, A., Rühlemann, C., Arz, H., Heil, G., Lohmann, G. 2007. Coupling of millennial-scale changes in sea surface temperature and precipitation off northeastern Brazil with high-latitude climate shifts during the last glacial period. Paleoceanography, 22, PA4206.

Jennerjahn, T. C., Ittekkot, V., Arz, H. W., Behling, H., Pätzold, J., Wefer, G. 2004. Asynchronous terrestrial and marine signals of climate change during Heinrich events. Science, 306, 2236- 2239.

Ji, J., Balsam, W., Chen, J. 2001. Mineralogic and climatic interpretations of the Luochuan loess section (China) based on diffuse reflectance spectrophotometry. Quaternary Research, 56, 23-30.

Kocurek, G. 1998. Aeolian system response to external forcing factors - a sequence stratigraphic view of the Saharan region. In: Alsharhan, A.S., Glennie, K.W., Whittle, G.L., Kendall, C.G.S.C. (Eds.), Quaternary Deserts and Climate Change. Balkema, Rotterdam, pp. 327-337.

Kocurek, G., Havholm, K. G. 1993. Eolian sequence stratigraphy-a conceptual framework. Memoirs-American Association of Petroleum Geologists, 393-393.

Koutavas, A., Lynch-Stieglitz, J., 2004. Variability of the marine ITCZ over the eastern Pacific during the past 30,000 years: regional perspective and global context. In: Diaz, H.F., Bradley, R.S. (Eds.), The Hadley Circulation: Present, Past, and Future. Kluwer, Dordrecht, Germany, pp. 347-369.

Kowsmann, R. O., Costa, M. D. A. 1979, Sedimentação quaternária da Margem Continental Brasileira e das áreas oceânicas adjacentes. REMAC, 8, 55pp.

Lambeck, K., Chappell, J. 2001. Sea level change through the Last Glacial Cycle. Science , 292 , 679-686. 
Lees, B. G., Hayne, M., Price, D. 1993. Marine transgression and dune initiation on western Cape York, northern Australia. Marine Geology, 114, 81-89.

Ledru, M. P., Mourguiart, P. 2001. Late glacial vegetation records in the Americas and climatic implications. Interhemispheric Climate Linkages. Academic Press, San Diego, p. 371-390.

Leighton, C. L., Thomas, D. S., Bailey, R. M. 2014. Reproducibility and utility of dune luminescence chronologies. Earth-Science Reviews, 129, 24-39.

Livingstone, I., Bristow, C., Bryant, R. G., Bullard, J., White, K., Wiggs, G. F., Thomas, D. S. 2010. The Namib Sand Sea digital database of aeolian dunes and key forcing variables. Aeolian Research, 2, 93-104.

Lisiecki, L. E., Raymo, M. E. 2005. A Pliocene-Pleistocene stack of 57 globally distributed benthic d180 records. Paleoceanography, 20, PA1003.

Macdonald, W. G., Rozendaal, A., de Meijer, R. J., 1997. Radiometric characteristics of heavy mineral deposits along the west coast of South Africa. Mineralium Deposita, 32, 371-381.

Martinho, C. T., Dillenburg, S. R., Hesp, P. A. 2008. Mid to late Holocene evolution of transgressive dunefields from Rio Grande do Sul coast, southern Brazil. Marine Geology, 256, 49-64.

Melo, A. B. C. 1997. Previsibilidade da precipitação na Região Semi-Árida do Nordeste do Brasil, durante a estação chuvosa, em função do comportamento diário das chuvas na pré-estação. Dissertação de Mestrado em Meteorologia. Departamento de Ciências Atmosféricas (DCA). Universidade Ferderal da Paraíba - UFPB. Campina Grande-PB. 100 pp.

Mohanty, A. K., Sengupta, D., Das, S. K., Vijayan, V., Saha, S. K. 2004. Natural radioactivity in the newly discovered high background radiation area on the eastern coast of Orissa, India. Radiation Measurements, 38, 153-165.

Molion, L. C. B., Bernardo, S.O. 2000. Dinâmica das chuvas no Nordeste brasileiro. Anais do congresso da Sociedade Brasileira de Meteorologia, 1334-1342. 
Morton, A. C., Hallsworth, C. R., 1994. Identifying provenance-specific features of detrital heavy mineral assemblages in sandstones. Sedimentary Geology, 90, 241-256.

Munyikwa, K., 2000. Cosmic ray contribution to environmental dose rates with varying overburden thickness. Ancient TL, 18, 27-34.

Murray, A., Wintle, A. G., 2000. Luminescence dating of quartz using an improved single-aliquot regenerative-dose protocol. Radiation Measurements, 32, 57-73.

Nace, T. E., Baker, P. A., Dwyer, G. S., Silva, C. G., Rigsby, C. A., Burns, S. J., Zhu, J. 2014. The role of North Brazil Current transport in the paleoclimate of the Brazilian Nordeste margin and paleoceanography of the western tropical Atlantic during the late Quaternary. Palaeogeography, Palaeoclimatology, Palaeoecology, 415, 3-13.

Nanson, G. C., Chen, X. Y., Price, D. M., 1992. Lateral migration, thermoluminescence chronology and colour variation of longitudinal dunes near Birdsville in the Simpson Desert, central Australia. Earth Surface Processes and Landforms, 17, 807-819.

Mendes, V. R., Giannini, P. C. F., Guedes, C. C. F., DeWitt, R., Andrade, H. A. D. A. 2015. Central Santa Catarina coastal dunefields chronology and their relation to relative sea level and climatic changes. Brazilian Journal of Geology, 45, 79-95.

Pessenda, L. C. R., de Souza Ribeiro, A., Gouveia, S. E. M., Aravena, R., Boulet, R., Bendassolli, J. A. 2004. Vegetation dynamics during the late Pleistocene in the Barreirinhas region, Maranhão State, northeastern Brazil, based on carbon isotopes in soil organic matter. Quaternary Research, 62, 183-193.

Peterson, L. C., Haug, G. H., Hughen, K. A., Röhl, U. 2000. Rapid changes in the hydrologic cycle of the tropical Atlantic during the last glacial. Science, 290, 1947-1951. 
Pye, K., Bowman, G.M., 1984. The Holocene marine transgression as a forcing function in episodic dune activity on the eastern Australain coast. In: Thom, B.G. (Ed.), Coastal Geomorphology in Australia. Academic Press, Sydney, 349 pp.

Pye, K., Tsoar, H. 2009. Aeolian Sand and Sand Dunes. 2nd. edition. SpringerVerlag, Berlin-Heildelberg, 458 pp.

Rhodes, E. J. 2011. Optically stimulated luminescence dating of sediments over the past 200,000 years. Annual Review of Earth and Planetary Sciences, 39, 461488.

Roskin, J., Porat, N., Tsoar, H., Blumberg, D. G., Zander, A. M. 2011. Age, origin and climatic controls on vegetated linear dunes in the northwestern Negev Desert (Israel). Quaternary Science Reviews, 30, 1649-1674.

Roy, P. S., Thom, B. G. 1981. Late Quaternary marine deposition in New South Wales and southern Queensland. J. Geol. Soc. Aust., 28, 471-490.

Sanchez Goñi, M. F., Harrison, S. P. 2010. Millennial-scale climate variability and vegetation changes during the Last Glacial: Concepts and terminology. Quaternary Science Reviews, 29, 2823-2827.

Sawakuchi, A. 0. 2006. Morfometria e simulação numérica de campos de dunas costeiros: estudo baseado em exemplos brasileiros. Instituto de Geociências da Universidade de São Paulo. Tese de doutoramento, 316 pp.

Sawakuchi, A. O., Kalchgruber, R., Giannini, P. C. F., Nascimento, D. R., Guedes, C. C. F., Umisedo, N. K. 2008. The development of blowouts and foredunes in the Ilha Comprida barrier (Southeastern Brazil): the influence of Late Holocene climate changes on coastal sedimentation. Quaternary Science Reviews, 27, 2076-2090.

Sawakuchi, A. O., Mendes, V. R., Pupim, F. D. N., Mineli, T. D., Ribeiro, L. M. A. L., Zular, A., Guedes, C. C. F., Giannini, P. C. F., Nogueira, L., Sallun Filho, W., Assine, M. L. 2016. Optically stimulated luminescence and isothermal thermoluminescence dating of high sensitivity and well bleached quartz from 
Brazilian sediments: from Late Holocene to beyond the Quaternary? Brazilian Journal of Geology, 46, 209-226.

Sitzia, L., Bertran, P., Bahain, J. J., Bateman, M. D., Hernandez, M., Garon, H., de Lafontaine, G., Mercier, N., Leroyer, C., Voinchet, P. 2015. The quaternary coversands of southwest France. Quaternary Science Reviews, 124, 84-105.

Stone, A. E. C., Thomas, D. S. G., 2008. Linear dune accumulation chronologies from the southwest Kalahari, Namibia: challenges of reconstructing late Quaternary palaeoenvironments from aeolian landforms. Quaternary Science Reviews, 27, 1667-1681.

Stríkis, N. M., Chiessi, C. M., Cruz, F. W., Vuille, M., Cheng, H., Souza Barreto, E. A., Bernal, J. P. 2015. Timing and structure of Mega-SACZ events during Heinrich Stadial 1. Geophysical Research Letters, 42, 5477-5484.

Telfer, M. W., Bailey, R. M., Burrough, S. L., Stone, A. E. S., Thomas, D. S. G., Wiggs, G. S. F., 2010. Understanding linear dune chronologies: insights from a simple accumulation model. Geomorphology, 120, 195-208.

Thom, B. 1978. Coastal sand deposition in southeast Australia during the Holocene. In: J. L. Davis and M. A. J. Williams (eds). Landform evolution in Australasia. A. N. U. Press, Camberra, 197-214.

Thompson, G. T., Goldstein, S. L. 2006. A radiometric calibration of the SPECMAP timescale. Quaternary Science Reviews, 25, 3207-3215.

Tsoar, H. 1990. The ecological background, deterioration and reclamation of desert dune sand. Agriculture Ecosystems and Environment, 33, 147-170.

Tsoar, H. 2005. Sand dunes mobility and stability in relation to climate. Physica a: Statistical Mechanics and Its Applications, 357, 50-56.

Tsoar, H. 2008. Land use and its effect on the mobilization and stabilization of the NW Negev sand dunes. In: Breckle SW, Yair A, Veste M (eds.) Arid dune ecosystems of ecological studies. Vol. 200 of Ecological Studies. Springer, Berlin, p. 79-90. 
Tsoar, H., Blumberg, D. G. 2002. Formation of parabolic dunes from barchan and transverse dunes along Israel's Mediterranean coast. Earth Surface Processes and Landforms, 27, 1147-1161.

Uvo, C. B. 1989. A Zona de Convergência Intertropical (ZCIT) e sua relação com a precipitação na Região Norte do Nordeste Brasileiro. Dissertação de Mestrado em Meteorologia, INPE. São José dos Campos, SP.

Vital, H., Gomes, M. P., Tabosa, W. F., Frazão, E. P., Santos, C. L. A., Júnior, P., Saraiva, J. 2010. Characterization of the Brazilian continental shelf adjacent to Rio Grande do Norte state, NE Brazil. Brazilian Journal of Oceanography, 58, 4354.

Vital, H. 2014. The north and northeast Brazilian tropical shelves. In: Chiocci, F. L., Chivas, A. R. (eds) 2014. Continental Shelves of the World: Their Evolution During the Last Glacio-Eustatic Cycle. Geological Society, London, Memoirs, 41, 35-46.

Wang, X., Auler, A. S., Edwards, R. L., Cheng, H., Cristalli, P. S., Smart, P. L., Shen, C. C. 2004. Wet periods in northeastern Brazil over the past $210 \mathrm{kyr}$ linked to distant climate anomalies. Nature, 432, 740-743.

Warren, A. 2013. Dunes: Dynamics, morphology, history. RGS-IBG book series. Wiley-Blackwell, West Sussex, UK. 219 pp.

Wentworth, C.K. 1922. A scale of grade and class terms for clastic sediments. The Journal of Geology, 377-392.

Wintle, A. G., Murray, A. S., 2006. A review of quartz optically stimulated luminescence characteristics and their relevance in single-aliquot regeneration dating protocols. Radiation Measurements, 41, 369-391.

Wood, W. W., Bailey, R. M., Hampton, B. A., Kraemer, T. F., Lu, Z., Clark, D. W., James, R. H. R., Al Ramadan, K., 2012. Rapid late Pleistocene/Holocene uplift and coastal evolution of the southern Arabian (Persian) Gulf. Quaternary Research, $77,215-220$. 
Young, A. R. M., Young, R., 2002. Soils in the Australian Landscape. Oxford University Press, Melbourne, 272 pp.

Yizhaq, H., Y. Ashkenazy, H. Tsoar. 2009. Sand dune dynamics and climate change: A modeling approach. Journal of Geophysical Research-Earth Surface, 114, F01023.

Zular A., Sawakuchi A. O., Guedes C. C. F., Mendes V. R., Nascimento Jr. D. R., Giannini P. C. F., Aguiar V. A. P., DeWitt, R. 2012. Late Holocene intensification of colds fronts in southern Brazil as indicated by dune development and provenance changes in the São Francisco do Sul coastal barrier. Marine Geology, 335, 64-77.

Zular, A., Sawakuchi, A. O., Guedes, C. C., Giannini, P. C. 2015. Attaining provenance proxies from OSL and TL sensitivities: Coupling with grain size and heavy minerals data from southern Brazilian coastal sediments. Radiation Measurements, 81, 39-45. 